Research Paper

\title{
Prognostic Significance of Young Age and Non-Bone Metastasis at Diagnosis in Patients with Metastatic Prostate Cancer: a SEER Population-Based Data Analysis
}

\author{
Yadong Guo ${ }^{1 \dagger}$, Shiyu Mao ${ }^{1 \dagger}$, Aihong Zhang2†, Ruiliang Wang1, Ziwei Zhang1, Junfeng Zhang1, Longsheng \\ Wang1, Wentao Zhang ${ }^{3}$, Yuan $\mathrm{Wu}^{3}$, Lin $\mathrm{Ye}^{1}$, Bin Yang ${ }^{\bowtie}$, Xudong Yao ${ }^{\circledR}$ \\ 1. Department of Urology, Shanghai Tenth People's Hospital, Tongji University, Shanghai, 200072, P.R. China \\ 2. Department of Medical Statistics, Tongii University School of Medicine, Shanghai, 200092, P.R. China \\ 3. Department of Urology, Shanghai Tenth People's Hospital, Anhui Medical University, Hefei 230032, P.R. China \\ † These authors contributed equally to this study. \\ $\square$ Corresponding authors: Email: yangbin710@163.com, Email: yaoxudong078@sina.com. Fax: +86-21-66305158; Tel: +86 02166301073. \\ (c) Ivyspring International Publisher. This is an open access article distributed under the terms of the Creative Commons Attribution (CC BY-NC) license \\ (https://creativecommons.org/licenses/by-nc/4.0/). See http://ivyspring.com/terms for full terms and conditions.
}

Received: 2018.08.26; Accepted: 2018.11.19; Published: 2019.01.01

\begin{abstract}
Objective: This study compared the clinicopathological features and survival of metastatic prostate cancer $(\mathrm{mPCa})$ after stratification by age and non-bone-related metastasis to identify prognostic factors.

Methods: Patients with mPCa between 2010 and 2015 were identified from the Surveillance, Epidemiology and End Results database and analyzed. The overall survival (OS) rate was assessed using the Kaplan-Meier curve and log-rank test as well as multivariate Cox regression analysis.

Results: Among the 10147 patients with mPCa, 5378 were classified as young ( $\leq 70$ years), 3140 were classified as middle-aged ( $70-82$ years), and 1629 were classified as elderly (> 82 years). The younger patients with a single site metastasis with non-regional lymph nodes (NRLN) had a better prognosis than those with bone metastasis [hazard ratio $(\mathrm{HR}), 0.59,95 \%$ confidence interval $(\mathrm{Cl})$, $0.47-0.73, P<0.001$ ], whereas patients with liver metastasis had the worst OS rate $(P=0.001)$. Moreover, patients in the middle-aged group with NRLN or lung metastasis had a better prognosis than those with bone metastasis $(P<0.05)$. The OS rate of patient with bone + liver and bone + brain metastasis was poorer $(P<0.001)$ than those with bone $+N R L N$ metastasis in the younger patients $(P<0.05)$. The elder patients with bone + lung metastasis had the worst OS (HR, 1.54; 95\% $\mathrm{Cl}, 1.25-1.90, \mathrm{P}<0.001)$, although the death risk of patients with bone + brain and bone $+\mathrm{NRLN}$ metastasis not significantly different $(P>0.05)$. However, the $O S$ of the patients with bone + liver metastasis remained the worst $(P<0.001)$.
\end{abstract}

Conclusions: Prostate cancer patients with lung metastasis or younger patients ( $\leq 70$ years old) with bone + lung metastases had better OS than patients with other types of metastasis or old age.

Key words: Metastatic prostate cancer, metastases, prognosis, age, surveillance, SEER data

\section{Introduction}

Prostate cancer is the second most common malignancy in men globally, accounting for 1.1 million new cases and more than 300,000 cancer-related deaths worldwide in 2012 [1]. In the United States, there will be an estimated 164,690 new cases of prostate cancer to be diagnosed and 29,430 cancer-related deaths in 2018 [2]. The risk factors in the development of prostate cancer include an older age, a family history of prostate cancer, and race [3, 4]. The median age of prostate cancer diagnosis is 66 years, and the majority of prostate cancer survivors $(64 \%)$ are over 70 years of age and it is rare to receive a 
prostate cancer diagnosis under the age of 50 years (less than 1\%) [5]. Prostate cancer frequently metastasizes to the lymph node and bone $[6,7]$. However, up to $15 \%$ of prostate cancer cases show metastasis to sites other than bone and regional lymph nodes at diagnosis [8,9]. Treatment is not required for cases of low-grade prostate cancer occurring in elderly men, whereas cases with a higher Gleason score and metastasis can be treated through chemoradiotherapy, endocrine therapy or surgery [10]. Recently, local treatment has been tried for metastatic prostate cancer $(\mathrm{mPCa})$, especially for oligo-metastatic cases [11].

Most localized prostate cancer cases have had favorable 5-year overall survival rate $(99 \%)$, whereas only $28 \%$ of distantly mPCa show 5 -year survival in the United States [10]. The prognosis of $\mathrm{mPCa}$ depends on different parameters of the clinicopathological factors, such as the level of the prostate-specific antigen (PSA) [12], the Gleason score [13], the lymph node status [14], and recurrence [15, 16]. A previous study showed that the age at diagnosis also plays an important role in the prognosis of prostate cancer [17]; there are few studies to date that have focused on the role of age in the survival of patients with mPCa. Recent studies have, however, evaluated the prognosis of castration-resistant prostate cancer with different metastatic sites [18, 19]. Thus, accurately understanding the characteristics of prostate cancer metastasis could help medical oncologists to predict the prognosis of prostate cancer and provide treatment decisions for these patients. In this study, we compared the clinicopathological features and survival of $\mathrm{mPCa}$ to stratify age and non-bone-related metastasis as prognostic factors.

\section{Methods}

\subsection{Database and patient selections}

The Surveillance Epidemiology and End Results (SEER) database is a population-based cancer registration system that covers approximately $28 \%$ of the total population in the United States [https://seer.cancer.gov/]. In this study, we utilized the SEER* Stat 8.3.5 software to query data from 18 SEER registries using the following criteria: primary prostate adenocarcinoma at all stages, including M1a-c [AJCC cancer staging manual, 7th edition [20]. Patients with unknown sites of cancer metastasis, unknown ages, and unknown survival data were excluded.

\subsection{Defining of metastasis sites}

The CS data collection system is a joint initiative, sponsored by the AJCC, to simplify staging data in cancer registrations. Specifically, the "CS mets at $d x$ $(2004+)^{\prime \prime}$ CS parameter includes information of the metastasis sites at diagnosis. We used this parameter in the search terms to obtain patients with information regarding metastatic sites, i.e., non-regional lymph nodes (NRLN) only metastasis (code, 11, 12, and 20), which has no visceral metastasis; bone only metastasis (code, 30), which has no visceral metastasis; bone + NRLN metastasis (code, 35), which has no visceral metastatic; all other sites \pm NRLN metastasis (Code, $38,40,50,58$, and 55). Cases of visceral metastasis were divided into the lung only, liver only, and brain only metastases as well as the bone + lung, bone + liver, and bone + brain metastasis, namely the bone-related metastases.

\subsection{Statistical analysis}

We utilized the X-tile software v3.6.1 (Yale University, New Haven, CT, USA) to determine the optimal cut-off values for age [21] and used SPSS v24.0 (SPSS Inc., Chicago, IL, USA) for all of the statistical analyses of the data. In brief, the clinicopathological characteristics of the patients were compared using Pearson's chi-square test and the Kaplan-Meier method was used to generate the overall survival for the log-rank test to assess differences in survival between groups. The multivariate Cox regression analysis was used to determine the association with overall survival (OS) rate and the OS rate was defined as the time from diagnosis of prostate cancer to death due to any cause. The hazards ratio (HR) and the 95\% confidence interval $(95 \% \mathrm{CI})$ were also generated for statistically significant values of data. A $p$ value $<0.05$ was considered to be statistically significant.

\section{Results}

\subsection{Characteristics of patients}

In this study, we searched the SEER database to identify a total of 10,471 patients with $\mathrm{mPCa}$ who were diagnosed between 2010 and 2015. And we used the X-tile software to divide age into three groups (Figure 1). For example, among the total population of patients, $5378(53 \%)$ were diagnosed at ages $\leq 70$ years old, which we classified as the younger-aged group, $3140(30.9 \%, 70-82$ years old) patients were classified as the middle-aged group, and 1629 (16.1\%) was placed in the elderly-aged group ( $>82$ years old). The median age at prostate cancer diagnosis was 70 years old with an overall median follow-up time of 16 months and an interquartile range (IQR) of 7-30 months.

Significant differences were observed in the insurance and marital status, race, the PSA level, Gleason score, $\mathrm{T}$ staging, $\mathrm{N}$ staging, surgery, 
radiotherapy, chemotherapy, and metastasis sites between patients $(\mathrm{P}<0.001$; Table 1$)$. Specifically, more Caucasian patients were diagnosed with $\mathrm{mPCa}$ in the elderly-aged group than in the younger- or middle-aged groups $(69.1 \%$ vs. $77.7 \%$ and $82.4 \%$, respectively, $\mathrm{P}<0.001)$. In addition, prostate cancer was more aggressive (T1/T2 vs. T3/T4 diseases) in patients in the younger-aged group than in the cases that were diagnosed in the middle- or elderly-aged groups $(25.1 \%$ vs. $19.9 \%$ and $17 \%$, respectively, $\mathrm{P}<$
0.001). The rate of the lymph node involvement was higher in the younger-aged group than in the middleor elderly-aged groups ( $33.7 \%$ vs. $23.5 \%$ and $17.1 \%, \mathrm{P}$ $<0.001$ ). However, data on the $\mathrm{T}$ stage and $\mathrm{N}$ stage were not available for all patients in this SEER database. In regards to treatment, the surgery and chemoradiotherapy rate was significantly higher in the patients in the younger- and middle-aged groups than in the patients in the elderly-aged group $(\mathrm{P}<$ $0.001)$.
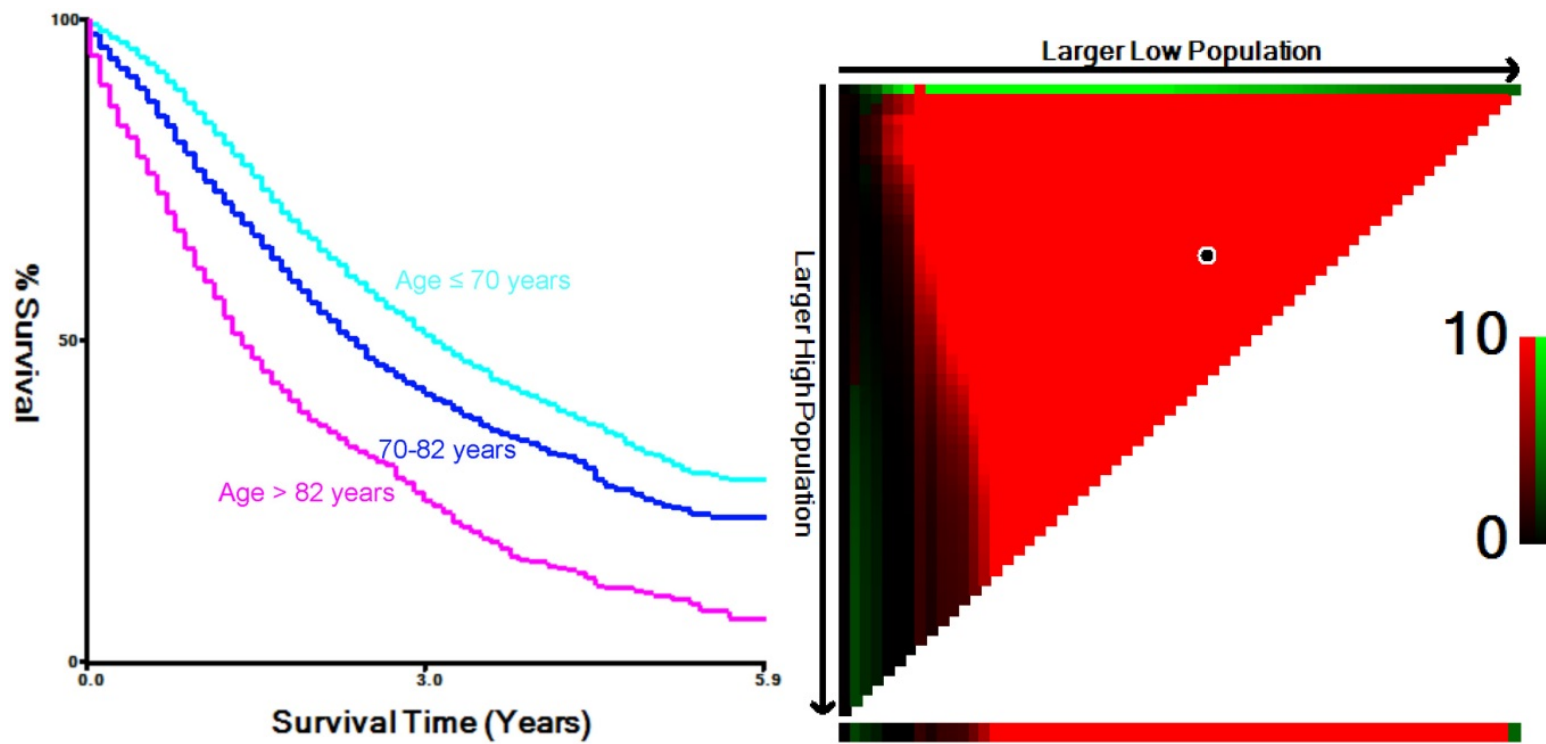

Figure 1. Estimation of the cut-off value for the age stratification as determined by the $\mathrm{X}$-tile software.

Table 1. Characteristics of patients with prostate cancer with distant metastasis from SEER 18 population-based registries by age groups.

\begin{tabular}{|c|c|c|c|c|c|}
\hline & Total & Age $\leq 70$ years & $70-82$ years & Age $>82$ years & P-value \\
\hline & $\mathrm{n}=10147$ & $\mathrm{n}=5378$ & $\mathrm{n}=3140$ & $\mathrm{n}=1629$ & \\
\hline Insurance, no. (\%) & & & & & $<0.001$ \\
\hline Insured & $8188(80.7)$ & $3997(74.3)$ & $2717(86.5)$ & $1474(90.5)$ & \\
\hline Uninsured & $405(4.0)$ & $341(6.3)$ & $47(1.5)$ & $17(1.0)$ & \\
\hline Any medicaid & $1261(12.4)$ & $876(16.3)$ & $288(9.2)$ & $97(6.0)$ & \\
\hline Unkown & $293(2.9)$ & $164(3.0)$ & $88(2.8)$ & $41(2.5)$ & \\
\hline Marital status, no. $(\%)$ & & & & & $<0.001$ \\
\hline Married & $5619(55.4)$ & $2855(53.1)$ & $1889(60.2)$ & $875(53.7)$ & \\
\hline Divorced/widowed & $1864(18.4)$ & $774(14.4)$ & $581(18.5)$ & $509(31.2)$ & \\
\hline singled & $1805(17.8)$ & $1258(23.4)$ & $406(12.9)$ & $141(8.7)$ & \\
\hline Unkown & $859(8.5)$ & $491(9.1)$ & $264(8.4)$ & $104(6.4)$ & \\
\hline Race, no. (\%) & & & & & $<0.001$ \\
\hline White & $7497(73.9)$ & $3714(69.1)$ & $2440(77.7)$ & $1343(82.4)$ & \\
\hline Black & $1903(18.8)$ & $1278(23.8)$ & $458(14.6)$ & $167(10.3)$ & \\
\hline Other & $653(6.4)$ & $332(6.2)$ & $212(6.8)$ & 109 (6.7) & \\
\hline Unkown & $94(0.9)$ & $54(1.0)$ & $30(1.0)$ & $10(0.6)$ & \\
\hline PSA in ng/mL, no. (\%) & & & & & $<0.001$ \\
\hline$\leq 20$ & $1762(17.4)$ & $978(18.2)$ & 607 (19.3) & $177(10.9)$ & \\
\hline $20-50$ & $1423(14.0)$ & $732(13.6)$ & $474(15.1)$ & $217(13.3)$ & \\
\hline$\geq 50$ & $6087(60.0)$ & $3300(61.4)$ & $1774(56.5)$ & $1013(62.2)$ & \\
\hline Unkown & $875(8.6)$ & $368(6.8)$ & $285(9.1)$ & $222(13.6)$ & \\
\hline Gleason score, no. $(\%)$ & & & & & $<0.001$ \\
\hline$\leq 7$ & 1309 (12.9) & $804(14.9)$ & 404 (12.9) & $101(6.2)$ & \\
\hline 8 & 1819 (17.9) & $1046(19.4)$ & $581(18.5)$ & 192(11.8) & \\
\hline 9 & $3448(34.0)$ & $1914(35.6)$ & $1085(34.6)$ & 449 (27.6) & \\
\hline 10 & $752(7.4)$ & $392(7.3)$ & $241(7.7)$ & $119(7.3)$ & \\
\hline Unkown & $2819(27.8)$ & $1222(22.7)$ & $829(26.4)$ & $768(47.1)$ & \\
\hline Derived AJCC T stage, no. (\%) & & & & & $<0.001$ \\
\hline$\leq \mathrm{T} 1$ & $2654(26.2)$ & $1443(26.8)$ & $864(27.5)$ & $347(21.3)$ & \\
\hline $\mathrm{T} 2$ & $2991(29.5)$ & $1568(29.2)$ & $987(31.4)$ & $436(26.8)$ & \\
\hline
\end{tabular}




\begin{tabular}{|c|c|c|c|c|c|}
\hline & Total & Age $\leq 70$ years & $70-82$ years & Age $>82$ years & P-value \\
\hline & $\mathrm{n}=10147$ & $n=5378$ & $\mathrm{n}=3140$ & $n=1629$ & \\
\hline T3 & $1099(10.8)$ & $684(12.7)$ & $308(9.8)$ & $107(6.6)$ & \\
\hline $\mathrm{T} 4$ & $1154(11.4)$ & $667(12.4)$ & $317(10.1)$ & $170(10.4)$ & \\
\hline $\mathrm{Tx}$ & $2249(22.2)$ & $1016(18.9)$ & $664(21.1)$ & $569(34.9)$ & \\
\hline Derived AJCC N stage, no. (\%) & & & & & $<0.001$ \\
\hline No & $5579(55.0)$ & $2742(51.0)$ & $1875(59.7)$ & $962(59.1)$ & \\
\hline N1 & $2829(27.9)$ & $1814(33.7)$ & $737(23.5)$ & $278(17.1)$ & \\
\hline $\mathrm{Nx}$ & $1739(17.1)$ & $822(15.3)$ & $528(16.8)$ & $389(12.9)$ & \\
\hline Surgery, no. (\%) & & & & & $<0.001$ \\
\hline Yes & 195 (1.9) & $169(3.1)$ & $21(0.7)$ & $5(0.3)$ & \\
\hline No/Unknown & $9952(98.1)$ & $5209(96.9)$ & $3119(99.3)$ & $1624(99.7)$ & \\
\hline Radiation, no. (\%) & & & & & $<0.001$ \\
\hline Yes & $2476(24.4)$ & $1538(28.6)$ & $678(21.6)$ & $260(16.0)$ & \\
\hline No/Unknown & $7671(75.6)$ & $3840(71.4)$ & $2462(78.4)$ & $1369(84.0)$ & \\
\hline Chemotherapy, no. (\%) & & & & & $<0.001$ \\
\hline Yes & $1094(10.8)$ & $808(15.0)$ & $253(8.1)$ & $33(2.0)$ & \\
\hline No/Unknown & $9053(89.2)$ & $4570(85.0)$ & $2887(91.9)$ & $1596(98.0)$ & \\
\hline Metastasis sites, no. (\%) & & & & & $<0.001$ \\
\hline NRLN only & $650(6.4)$ & $401(7.5)$ & $187(6.0)$ & $62(3.8)$ & \\
\hline Bone only & $7161(70.6)$ & $3565(66.3)$ & $2339(74.5)$ & $1257(77.2)$ & \\
\hline Lung only & $140(1.4)$ & $65(1.2)$ & $44(1.4)$ & $31(1.9)$ & \\
\hline Liver only & $72(0.7)$ & $40(0.7)$ & $19(0.6)$ & $13(0.8)$ & \\
\hline Brain only & $17(0.2)$ & $9(0.2)$ & $6(0.2)$ & $1(0.1)$ & \\
\hline Bone+NRLN & $1313(12.9)$ & $863(16.0)$ & $307(9.8)$ & $143(8.8)$ & \\
\hline Bone+Lung & $546(5.4)$ & $296(5.5)$ & $168(5.4)$ & $82(5.0)$ & \\
\hline Bone+Liver & $203(2.0)$ & $112(2.1)$ & $58(1.8)$ & $33(2.0)$ & \\
\hline Bone+Brain & $45(0.4)$ & $27(0.5)$ & $12(0.4)$ & $6(0.4)$ & \\
\hline
\end{tabular}

Abbreviations: NRLN=non-regional lymph nodes

\subsection{Age-related patterns of prostate cancer metastasis}

Regarding the observation of single metastatic sites in these prostate cancer patients, bone metastasis was the most common metastatic site $(70.6 \%)$, followed by NRLN (6.4\%), the lung (1.4\%), liver $(0.7 \%)$, and brain $(0.2 \%)$. In cases with multiple metastatic sites, bone-related metastases occurred commonly at the bone + NRLN $(12.9 \% ; n=1313)$. The 8040 cases of single site metastasis were compared to the 2107 bone-related metastatic sites. We found that, compared to the results found in patients with a single metastatic site, bone and lung metastases were more often observed in patients in the older-aged group than in patients in the younger- or middle-aged groups $(77.2 \%$ vs. $66.3 \%$ or $74.5 \%$, respectively, or $1.9 \%$ vs. $1.2 \%$ and $1.4 \%$, respectively; $\mathrm{P}<0.001$ ). However, the proportion of NRLN metastasis was lower in patients of the older-aged group than in patients of the younger- or middle-aged groups (3.8\% vs. $7.5 \%$ and $6.0 \%$, respectively, $\mathrm{P}<0.001$ ).

\subsection{Univariate survival analysis of patients with $\mathrm{mPCa}$}

We then performed a univariate analysis of the patients with a single metastasis site for survival significance (Table 2). Our data shows that age, insurance and marital status, race, the PSA level, Gleason score, tumor T, N, and M stages, surgery, and radiotherapy were prognostic factors for the overall survival (OS) rate $(\mathrm{P}<0.05)$. Moreover, compared with the cases of bone metastases, patients with
NRLN or lung metastasis had a better OS rate $(\mathrm{P}<$ $0.05)$, whereas patients with liver metastasis had a poor OS rate $(P<0.05)$. However, there was no statistical significance in the OS rate of patients with brain metastasis $(\mathrm{P}=0.19)$.

Furthermore, analysis of the data regarding patients with bone-related metastases showed that age, race, PSA level, Gleason score, tumor T and M stages, radiotherapy, and chemotherapy all had an effect on the OS rate $(\mathrm{P}<0.05$; Table 3$)$. Compared with the data regarding patients with bone + NRLN metastasis, the OS rate of patients with bone + lung, bone + liver and bone + brain metastasis were poor $(\mathrm{P}$ $<0.05)$. Figure 2 shows the OS rate of the patients with a single metastasis and patients with bone-related metastasis.

\subsection{Multivariate survival analysis of patients with single site metastases stratified by age}

We then performed multivariate analysis and found that metastasis sites, together with age, insurance and marital status, race, PSA level, Gleason score, tumor $\mathrm{T}$ and $\mathrm{N}$ stages, and surgery, were all independent prognostic predictors for the OS rate $(\mathrm{P}<$ 0.05; Table 2). We then stratified our data by age groups and found that there was a significant difference in the OS rate of patients with different metastatic sites $(\mathrm{P}<0.001$, Fig. 3$)$. In the younger age group, patients with NRLN metastasis had a better OS rate than those with bone metastasis (HR, $0.59,95 \% \mathrm{CI}$, $0.47-0.73, \mathrm{P}<0.001$; Table 4$)$. In this age group, cases of liver metastasis tended to have the worst OS rate, although patients with PCa lung, brain, and bone 
metastases had a similar prognosis $(\mathrm{P}>0.05$; Table 4$)$. In the middle-aged group, the risk of death for patients with NRLN and lung metastasis was similar. However, the prognosis of patients with NRLN and lung metastasis was better than that of cases of bone metastasis $(\mathrm{P}<0.05$; Table 4). Furthermore, the prognosis of patients with the liver and brain metastases was similar to those with bone metastases. In the older-aged group, there was no significant difference in the prognosis of patients with NRLN, lung, or brain metastasis ( $\mathrm{P}>0.05$; Table 4). However, in this age group, the OS rate of patients with liver metastasis was still the worst $(P=0.009$; Table 4$)$.

Table 2. Univariate and multivariate analysis of overall survival (OS) rates of patients with single metastases.

\begin{tabular}{|c|c|c|c|c|}
\hline & $\begin{array}{l}\text { Unvariate } \\
\text { analysis }\end{array}$ & & $\begin{array}{l}\text { Multivariate } \\
\text { analysis }\end{array}$ & \\
\hline & HRs $(95 \% \mathrm{CI})$ & P-value & HRs $(95 \% \mathrm{CI})$ & P-value \\
\hline \multicolumn{5}{|l|}{ Age } \\
\hline$\leq 70$ years & 1 (Ref) & & 1 (Ref) & \\
\hline $70-82$ years & $1.384(1.282-1.495)$ & $<0.001$ & & $<0.001$ \\
\hline$>82$ years & $2.471(2.268-2.692)$ & $<0.001$ & $1.600(1.490-1.718)$ & $<0.001$ \\
\hline Insurance & & $<0.001$ & & $<0.001$ \\
\hline Insured & 1 (Ref) & & 1 (Ref) & \\
\hline Uninsured & $1.021(0.852-1.224)$ & 0.823 & 1.077 (0.895-1.295) & 0.431 \\
\hline Any medicaid & $1.270(1.148-1.406)$ & $<0.001$ & $1.233(1.110-1.370)$ & $<0.001$ \\
\hline Unkown & $0.937(0.772-1.136)$ & 0.508 & $1.028(0.842-1.255)$ & 0.786 \\
\hline Marital status & & $<0.001$ & & $<0.001$ \\
\hline Married & 1 (Ref) & & 1 (Ref) & \\
\hline Divorced/widowed & $1.506(1.384-1.638)$ & $<0.001$ & $1.263(1.159-376)$ & $<0.001$ \\
\hline singled & $1.223(1.125-1.352)$ & $<0.001$ & $1.163(1.056-1.281)$ & 0.002 \\
\hline Unkown & 0.949 (0.835-1.079) & 0.427 & $0.935(0.819-1.068)$ & 0.322 \\
\hline Race & & $<0.001$ & & $<0.001$ \\
\hline White & 1 (Ref) & & 1 (Ref) & \\
\hline Black & $1.072(0.985-1.167)$ & 0.106 & $1.082(0.991-1.182)$ & 0.079 \\
\hline Other & $0.767(0.659-0.893)$ & 0.001 & $0.736(0.631-0.857)$ & $<0.001$ \\
\hline Unkown & $0.344(0.185-641)$ & 0.001 & $0.386(0.207-0.719)$ & 0.003 \\
\hline PSA in $n g / m L$ & & $<0.001$ & & $<0.001$ \\
\hline$\leq 20$ & 1 (Ref) & & 1 (Ref) & \\
\hline $20-50$ & 1.302 (1.147-1.478) & $<0.001$ & 1.214 (1.068-1.379) & 0.003 \\
\hline$\geq 50$ & $1.855(1.680-2.048)$ & $<0.001$ & $1.478(1.334-1.638)$ & $<0.001$ \\
\hline Unkown & 1.955 (1.706-2.240) & $<0.001$ & 1.406 (1.221-1.618) & $<0.001$ \\
\hline Gleason score & & $<0.001$ & & $<0.001$ \\
\hline$\leq 7$ & 1 (Ref) & & 1 (Ref) & \\
\hline 8 & $1.410(1.230-1.617)$ & $<0.001$ & $1.337(1.165-1.534)$ & $<0.001$ \\
\hline 9 & $1.934(1.712-2.185)$ & $<0.001$ & 1.841 (1.627-2.083) & $<0.001$ \\
\hline 10 & $2.697(2.306-3.154)$ & $<0.001$ & $2.471(2.108-2.896)$ & $<0.001$ \\
\hline Unkown & $3.061(2.705-3.463)$ & $<0.001$ & $2.323(2.027-2.661)$ & $<0.001$ \\
\hline Derived AJCC T stage & & $<0.001$ & & $<0.001$ \\
\hline$\leq \mathrm{T} 1$ & 1 (Ref) & & 1 (Ref) & \\
\hline $\mathrm{T} 2$ & $1.076(0.984-1.177)$ & 0.109 & $0.991(0.905-1.086)$ & 0.854 \\
\hline T3 & $0.840(0.736-0.957)$ & 0.009 & $0.884(0.773-1.011)$ & 0.071 \\
\hline $\mathrm{T} 4$ & $1.522(1.350-1.716)$ & $<0.001$ & 1.259 (1.111-1.426) & $<0.001$ \\
\hline $\mathrm{Tx}$ & $1.725(1.570-1.894)$ & $<0.001$ & $1.133(1.006-1.276)$ & 0.039 \\
\hline Derived AJCC N stage & & $<0.001$ & & 0.039 \\
\hline No & 1 (Ref) & & 1 (Ref) & \\
\hline N1 & $0.875(0.799-0.958)$ & 0.004 & $0.912(0.827-1.005)$ & 0.064 \\
\hline $\mathrm{Nx}$ & $1.392(1.281-1.512)$ & $<0.001$ & $1.062(0.969-1.163)$ & 0.199 \\
\hline \multicolumn{5}{|l|}{ Surgery } \\
\hline Yes & $0.276(0.188-0.406)$ & $<0.001$ & $0.579(0.390-0.860)$ & 0.007 \\
\hline No/Unknown & 1 (Ref) & & 1 (Ref) & \\
\hline \multicolumn{5}{|l|}{ Radiation } \\
\hline Yes & $0.912(0.843-0.986)$ & 0.021 & - & \\
\hline No/Unknown & 1 (Ref) & & & \\
\hline \multicolumn{5}{|l|}{ Chemotherapy } \\
\hline Yes & $0.919(0.798-1.058)$ & 0.24 & - & \\
\hline No/Unknown & 1 (Ref) & & & \\
\hline
\end{tabular}

\begin{tabular}{lllll}
\hline & $\begin{array}{l}\text { Unvariate } \\
\text { analysis }\end{array}$ & \multicolumn{3}{l}{$\begin{array}{l}\text { Multivariate } \\
\text { analysis }\end{array}$} \\
\hline & HRs (95\% CI) & P-value & HRs (95\% CI) & P-value \\
\hline Metastasis sites & & $<0.001$ & & $<0.001$ \\
Bone only & 1 (Ref) & & 1 (Ref) & \\
NRLN only & $0.606(0.522-0.702)$ & $<0.001$ & $0.641(0.548-0.749)$ & $<0.001$ \\
Lung only & $0.733(0.552-0.971)$ & $\mathbf{0 . 0 3 1}$ & $0.716(0.539-0.951)$ & $\mathbf{0 . 0 2 1}$ \\
Liver only & $2.045(1.523-2.745)$ & $<0.001$ & $1.937(1.439-2.605)$ & $<0.001$ \\
Brain only & $1.482(0.820-2.679)$ & 0.193 & $1.340(0.739-2.428)$ & 0.335 \\
\hline $\begin{array}{l}\text { Abbreviations: HR=Hazard ratio; CI=confidence interval; NRLN=non-regional } \\
\text { lymph nodes }\end{array}$
\end{tabular}

Table 3. Univariate and multivariate analysis of overall survival (OS) rates of patients with bone-related metastases.

\begin{tabular}{|c|c|c|c|c|}
\hline & $\begin{array}{l}\text { Unvariate } \\
\text { analysis }\end{array}$ & & $\begin{array}{l}\text { Multivariate } \\
\text { analysis }\end{array}$ & \\
\hline & HRs $(95 \% \mathrm{CI})$ & P-value & HRs $(95 \% \mathrm{CI})$ & P-value \\
\hline \multicolumn{5}{|l|}{ Age } \\
\hline$\leq 70$ years & 1 (Ref) & & 1 (Ref) & \\
\hline$>70$ years & $1.642(1.454-1.854)$ & $<0.001$ & $1.545(1.363-1.752)$ & $<0.001$ \\
\hline Insurance & & 0.559 & & \\
\hline Insured & 1 (Ref) & & - & \\
\hline Uninsured & $0.859(0.660-1.120)$ & 0.262 & & \\
\hline Any medicaid & $0.978(0.830-1.153)$ & 0.79 & & \\
\hline Unkown & $1.174(0.800-1.723)$ & 0.413 & & \\
\hline Marital status & & 0.083 & & \\
\hline Married & 1 (Ref) & & - & \\
\hline Divorced/widowed & $1.216(1.036-426)$ & 0.016 & & \\
\hline singled & $1.115(0.959-1.298)$ & 0.157 & & \\
\hline Unkown & $0.995(0.786-1.259)$ & 0.964 & & \\
\hline Race & & 0.013 & & 0.003 \\
\hline White & 1 (Ref) & & 1 (Ref) & \\
\hline Black & $0.904(0.783-1.044)$ & 0.171 & $0.868(0.750-1.005)$ & 0.058 \\
\hline Other & $0.766(0.590-0.994)$ & 0.045 & $0.708(0.545-0.920)$ & 0.01 \\
\hline Unkown & $0.091(0.013-0.644)$ & 0.016 & $0.110(0.015-0.783)$ & 0.028 \\
\hline PSA in $n g / m L$ & & 0.008 & & \\
\hline$\leq 20$ & 1 (Ref) & & - & \\
\hline $20-50$ & $1.071(0.821-1.396)$ & 0.614 & & \\
\hline$\geq 50$ & $1.071(0.880-1.304)$ & 0.495 & & \\
\hline Unkown & $1.577(1.182-2.104)$ & 0.002 & & \\
\hline Gleason score & & $<0.001$ & & $<0.001$ \\
\hline$\leq 7$ & 1 (Ref) & & 1 (Ref) & \\
\hline 8 & $0.912(0.695-1.197)$ & 0.507 & $0.903(0.687-1.187)$ & 0.464 \\
\hline 9 & $1.189(0.936-1.510)$ & 0.157 & $1.187(0.933-1.512)$ & 0.163 \\
\hline 10 & $1.649(1.238-2.195)$ & 0.001 & $1.670(1.250-2.231)$ & 0.001 \\
\hline Unkown & $1.597(1.266-2.015)$ & $<0.001$ & 1.398 (1.094-1.786) & 0.007 \\
\hline Derived AJCC T stage & & $<0.001$ & & 0.006 \\
\hline$\leq \mathrm{T} 1$ & 1 (Ref) & & 1 (Ref) & \\
\hline $\mathrm{T} 2$ & $1.142(0.944-1.381)$ & 0.17 & $1.060(0.875-1.285)$ & 0.552 \\
\hline $\mathrm{T} 3$ & $1.023(0.796-1.315)$ & 0.861 & $0.996(0.773-1.284)$ & 0.978 \\
\hline $\mathrm{T} 4$ & $1.511(1.235-1.848)$ & $<0.001$ & 1.394 (1.134-1.713) & 0.002 \\
\hline $\mathrm{Tx}$ & $1.432(1.188-1.725)$ & $<0.001$ & $1.198(0.971-1.478)$ & 0.091 \\
\hline \multicolumn{2}{|l|}{ Derived AJCC N stage } & 0.17 & & \\
\hline No & 1 (Ref) & & - & \\
\hline N1 & $0.929(0.811-1.065)$ & 0.291 & & \\
\hline Nx & $1.086(0.906-1.303)$ & 0.372 & & \\
\hline \multicolumn{5}{|l|}{ Surgery } \\
\hline Yes & $0.726(0.362-1.457)$ & 0.368 & & \\
\hline No/Unknown & 1 (Ref) & & - & \\
\hline \multicolumn{5}{|l|}{ Radiation } \\
\hline Yes & 1.181 & 0.016 & 1.221 (1.064-1.401) & 0.004 \\
\hline No/Unknown & 1 (Ref) & & 1 (Ref) & \\
\hline \multicolumn{5}{|l|}{ Chemotherapy } \\
\hline Yes & $0.731(0.592-0.903)$ & 0.004 & $0.674(0.544-0.836)$ & $<0.001$ \\
\hline No/Unknown & 1 (Ref) & & 1 (Ref) & \\
\hline Metastasis sites & & $<0.001$ & & $<0.001$ \\
\hline Bone+NRLN & 1 (Ref) & & 1 (Ref) & \\
\hline Bone+Lung & 1.171 (1.015-1.352) & 0.03 & $1.198(1.036-1.384)$ & 0.015 \\
\hline Bone+Liver & $2.137(1.785-2.559)$ & $<0.001$ & $2.167(1.805-2.603)$ & $<0.001$ \\
\hline Bone+Brain & $1.762(1.234-2.515)$ & 0.002 & $1.684(1.174-2.416)$ & 0.005 \\
\hline
\end{tabular}



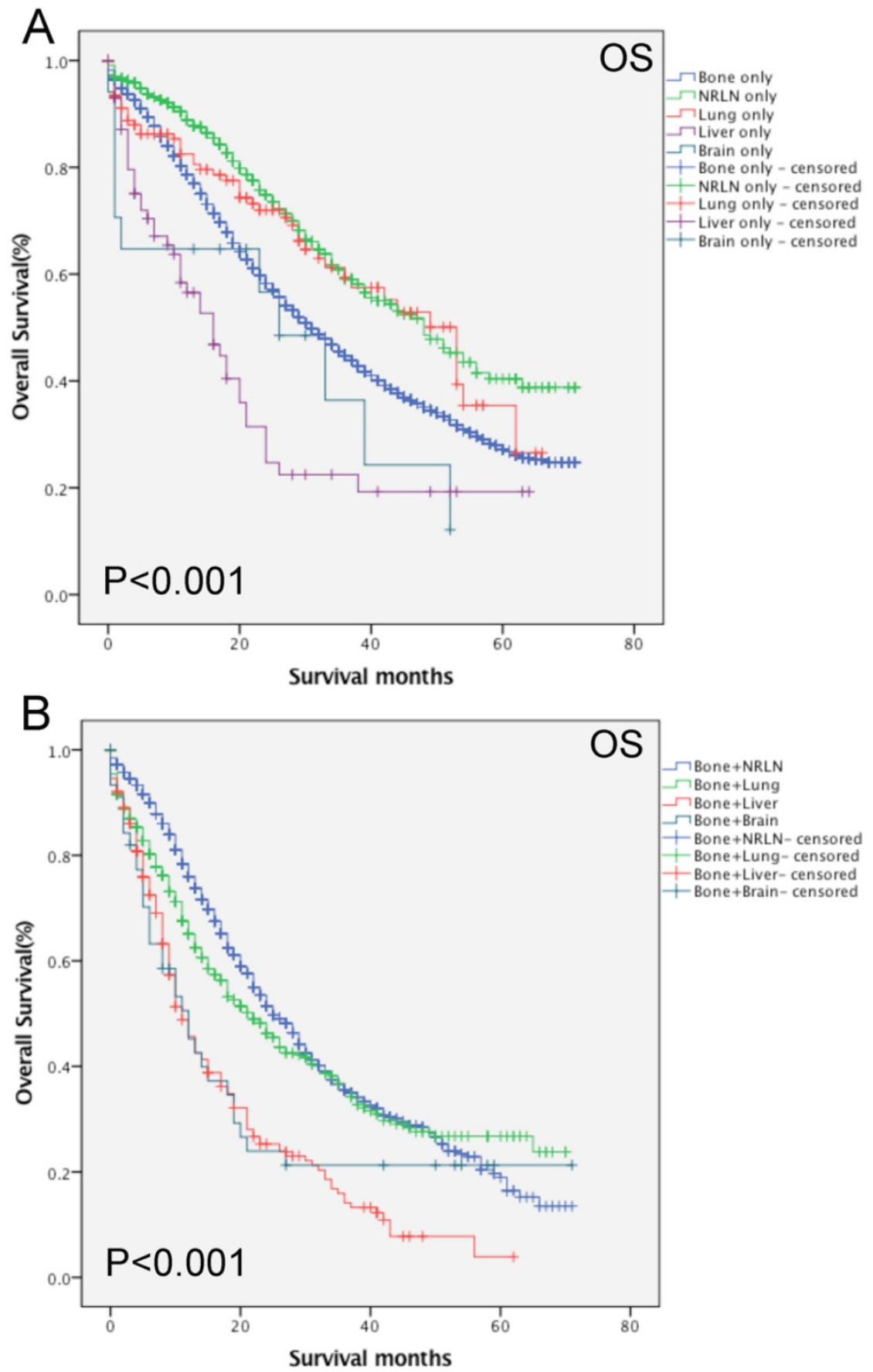

Figure 2. Comparison of the overall survival rates of patients with prostate cancer with single (A) and bone-related (B) metastatic sites analyzed by using the Kaplan-Meier curves.

\subsection{Multivariate survival analysis of patients with bone-related metastases stratified by age}

Our data shows that the metastatic site, together with age, race, Gleason score, tumor $\mathrm{T}$ stage, radiotherapy, and chemotherapy, were all independent prognostic predictors for the OS rate of patients with mPCa $(\mathrm{P}<0.001$; Table 3). Among the patients with bone-related metastases, there was poor an OS rate in patients with a Gleason score of 10 or more (HR, 1.67, 95\% CI, 1.25-2.23, $\mathrm{P}<0.001$ ) of $\mathrm{T} 4$ stage $(\mathrm{HR}, 1.39,95 \% \mathrm{CI}, 1.13-2.71, \mathrm{P}=0.002)$.
Moreover, the Kaplan-Meier curves that were stratified by age show that there was a significant difference in the OS rate among patients with different organ metastases $(\mathrm{P}<0.001$; Fig. 4). We analyzed the difference in the OS rate of patients with bone-related metastases among these three groups, stratified by patients' age, and found that the metastatic sites in the middle- and elderly-aged groups had the same prognosis in terms of the bone-related metastases; thus, the data from these two groups were combined. In the younger aged group, 
there was no statistical difference in the OS rate in patients with bone + NRLN and patients with bone + lung metastasis ( $\mathrm{P}>0.53$; Table 5). Compared to the results of patients with bone + NRLN metastasis, the OS rate of patients with bone + brain and bone + liver metastasis was poor $(\mathrm{HR}, 1.95,95 \% \mathrm{CI}, 1.20-3.16, \mathrm{P}=$ 0.007 or HR, 2.20, 95\%CI, 1.72-2.81, P < 0.001; Table 5). However, patients with bone + liver metastasis showed the worst OS rate.

In the elderly-aged group, the OS rate of patients with bone + liver or bone + lung metastasis was worse than those of patients with of bone + NRLN metastasis (HR, 2.22, 95\% CI, 1.68-2.92, $\mathrm{P}<0.001$ or
HR, 1.54, 95\% CI: 1.254 1.900, $\mathrm{P}<0.001$; Table 5). Patients with bone + liver metastasis had a higher risk of death than patients with bone + lung metastasis. There was no statistical significance in the difference in the OS rate of patients with bone + brain and bone + NRLN metastasis ( $P>0.05$; Table 5). Thus, our current study suggests that the OS rate of patients with bone + lung or bone + NRLN metastasis was similar in the younger patient population. However, the difference in the OS rate of patients with bone + brain or bone + NRLN metastasis in elderly-aged patients was not statistically significant.
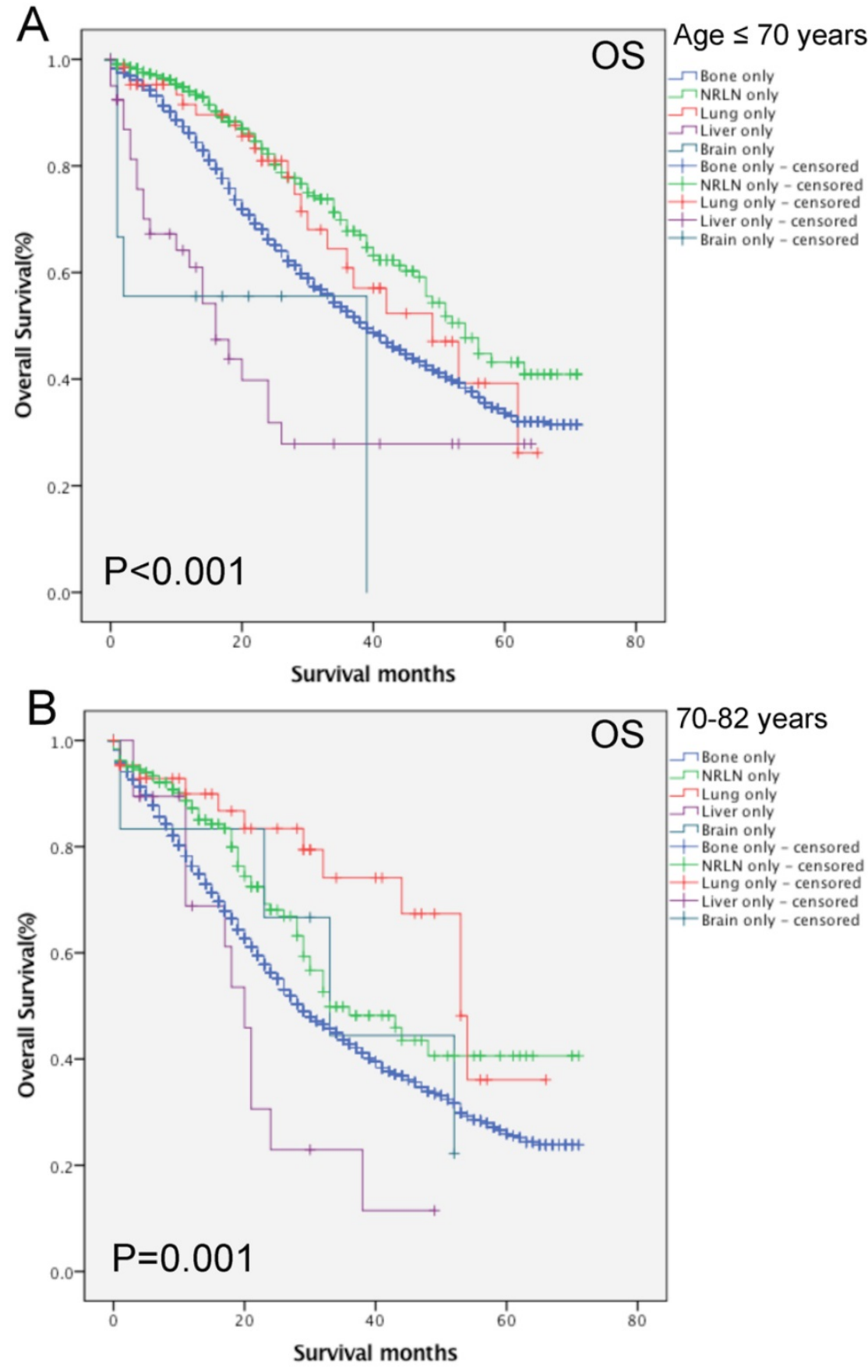


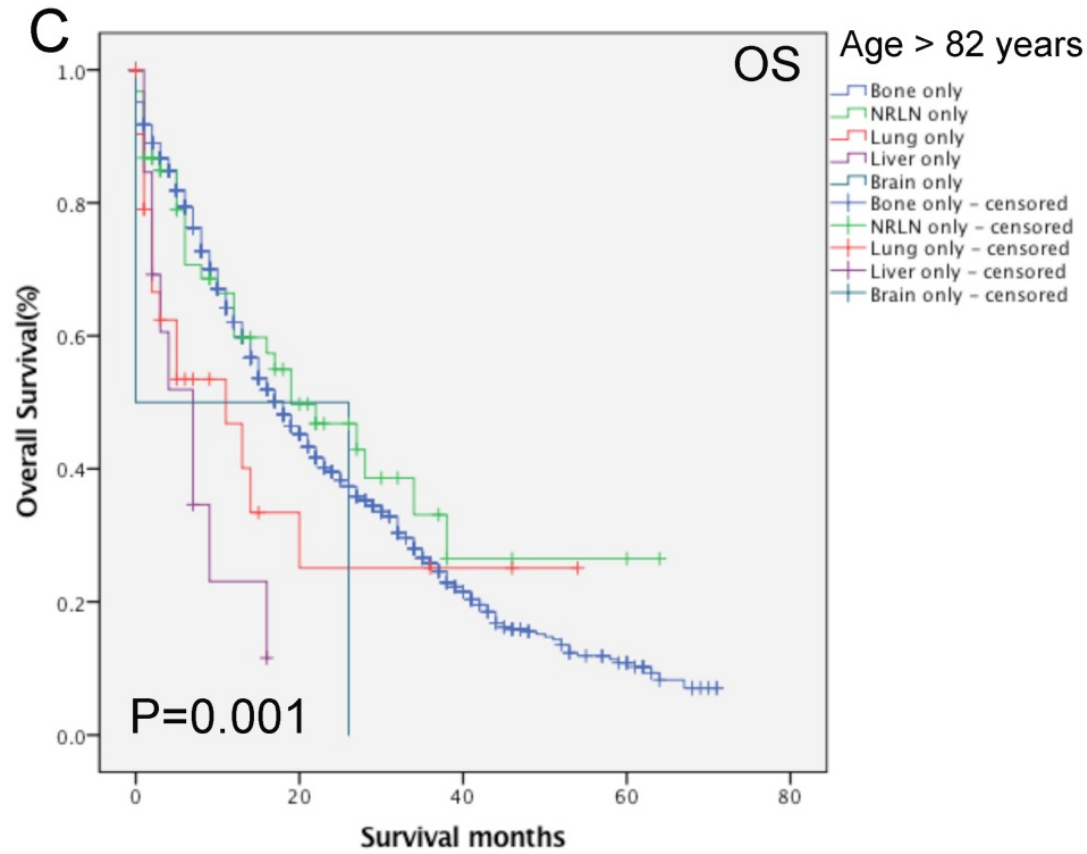

Figure 3. Comparison of the overall survival rates of patients with prostate cancer with single metastatic sites stratified with age, as analyzed by using the Kaplan-Meier curves. $A=$ young aged group ( $<70$ years of age), $B=$ middle-aged group ( $70-82$ years of age), $C=$ elderly aged group $(>82$ years of age).

Table 4. Multivariate Cox regression analysis of overall survival (OS) rates of the single metastatic site by age groups

\begin{tabular}{|c|c|c|c|c|c|c|c|c|}
\hline Age $\leq 70$ years & Multivariate analysis & & $70-82$ years & Multivariate analysis & & Age $>82$ years & Multivariate analysis & \\
\hline & HRs $(95 \% \mathrm{CI})$ & P-value & & HRs $(95 \% \mathrm{CI})$ & P-value & & HRs $(95 \% \mathrm{CI})$ & P-value \\
\hline Metastasis sites & & $<0.001$ & Metastasis sites & & $<0.001$ & Metastasis sites & & 0.016 \\
\hline Bone only & 1 (Ref) & & Bone only & 1 (Ref) & & Bone only & 1 (Ref) & \\
\hline NRLN only & $0.590(0.475-0.734)$ & $<0.001$ & NRLN only & $0.632(0.487-0.821)$ & 0.001 & NRLN only & $0.754(0.523-1.088)$ & 0.131 \\
\hline Lung only & $0.737(0.468-1.161)$ & 0.189 & Lung only & $0.429(0.242-0.761)$ & 0.004 & Lung only & $1.412(0.857-2.327)$ & 0.176 \\
\hline Liver only & $2.088(1.362-3.202)$ & 0.001 & Liver only & $1.439(0.811-2.551)$ & 0.213 & Liver only & $2.327(1.240-4.369)$ & 0.009 \\
\hline Brain only & $2.260(0.913-5.337)$ & 0.079 & Brain only & $0.968(0.358-2.612)$ & 0.948 & Brain only & $2.024(0.499-8.210)$ & 0.324 \\
\hline
\end{tabular}

Abbreviations: $\mathrm{HR}=$ Hazard ratio; $\mathrm{CI}=$ confidence interval; NRLN=non-regional lymph nodes

Table 5. Multivariate Cox regression analysis of overall survival (OS) rates of the bone-related metastases sites by age groups.

\begin{tabular}{lllll}
\hline Age $\leq$ 70 years & Multivariate analysis & & Age $>$ 70 years & Multivariate analysis \\
\hline & HRs $(\mathbf{9 5} \% \mathbf{C I})$ & P-value & & HRs (95\% CI) \\
\hline Metastasis sites & & $<\mathbf{0 . 0 0 1}$ & Metastasis sites & \\
Bone+NRLN & $1($ Ref $)$ & & Bone+NRLN & $1($ Ref $)$ \\
Bone+Lung & $0.937(0.762-1.151)$ & 0.534 & Bone+Lung & $1.544(1.254-1.900)$ \\
Bone+Liver & $2.203(1.725-2.815)$ & $<\mathbf{0 . 0 0 1}$ & Bone+Liver & $2.222(1.688-2.926)$ \\
Bone+Brain & $1.952(1.202-3.169$ & $\mathbf{0 . 0 0 7}$ & Bone+Brain & $1.538(0.889-2.661)$ \\
\hline
\end{tabular}

Abbreviations: $\mathrm{HR}=$ Hazard ratio; $\mathrm{CI}=$ confidence interval; NRLN=non-regional lymph nodes

\section{Discussion}

During the past three decades, the incidence of cancer has increased globally and cancer prognosis is inversely associated with cancer invasion and metastasis [22]. Metastasis is a truly multifaceted process that involves tumor cell proliferation, migration, and invasion to nearby or distant lymph nodes or to the blood stream followed by the establishment of a metastatic site, angiogenesis, and formation of metastatic tumor lesions [23]. Prostate cancer usually metastasizes through lymph nodes to the bone or other organs. Approximately 15\% of patients with prostate cancer have visceral metastases [6]. To date, there is no standard treatment for patients with $\mathrm{mPCa}$; thus, the identification of patients with prostate cancer that have a better prognosis could provide us with guidelines for the selection of different treatment options. 

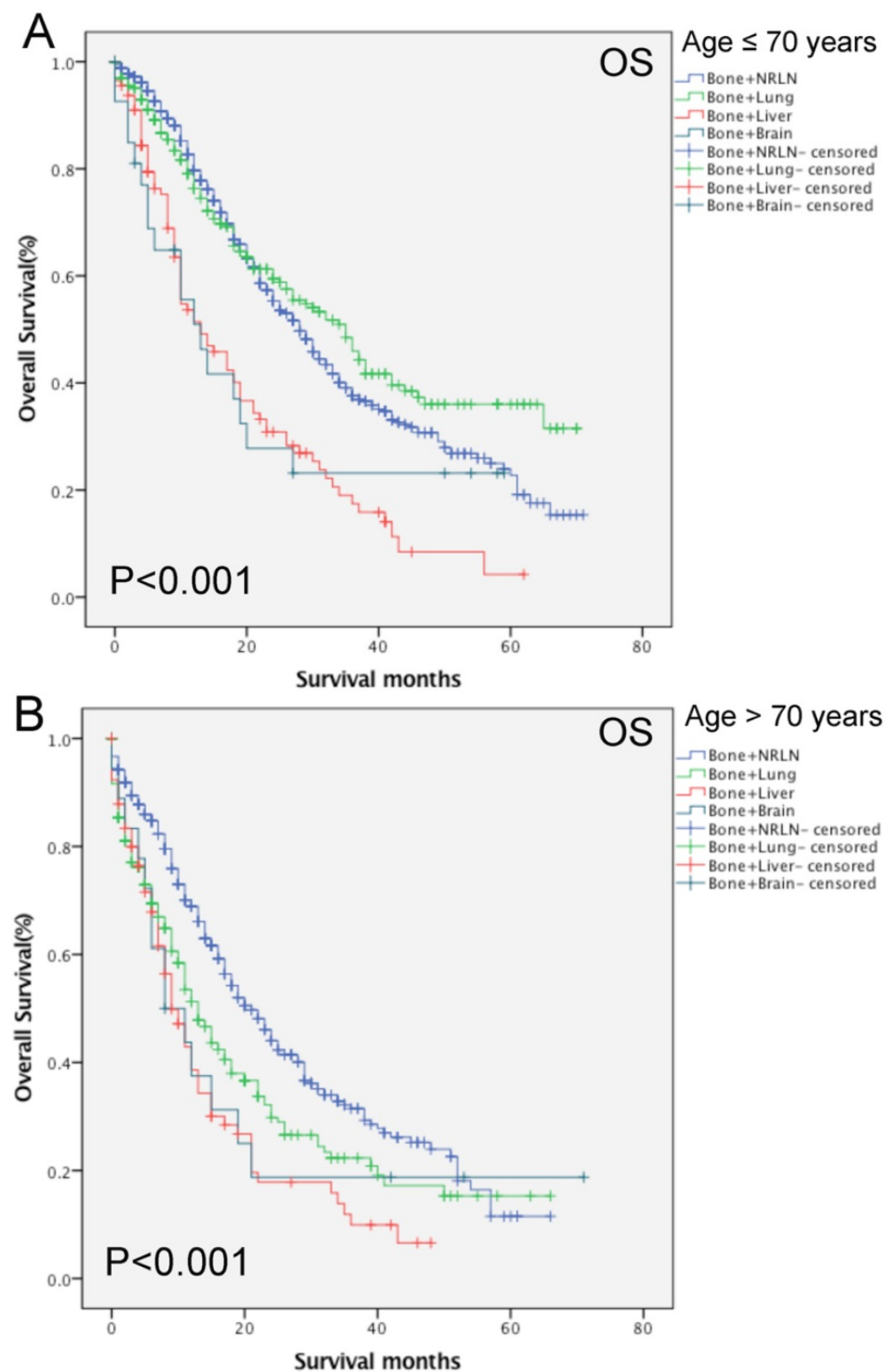

Figure 4. Comparison of overall survival of prostate cancer patients with bone-related metastatic sites stratified with age analyzed by using the Kaplan-Meier curves. $A=$ young aged group ( $\leq 70$ years of age), $B=$ middle-aged and elderly aged group ( $>70$ years of age).

In the current study, we compared the clinicopathological features and overall survival rate of patients with mPCa after stratification by the age of patients and by the observation of a single metastasis vs. bone-related metastases. We found that bone metastasis was the most common type of metastasis $(70.6 \%)$, followed by NRLN $(6.4 \%)$, the lung $(1.4 \%)$, liver $(0.7 \%)$, and brain $(0.2 \%)$. In cases of mPCa with multiple metastatic sites, bone-related metastases occurred commonly at the bone $+\operatorname{NRLN}(12.9 \% ; n=$ 1313). The multivariate survival analysis of patients with single site metastases showed that metastasis sites, age, insurance and marital status, race, PSA level, Gleason score, tumor $\mathrm{T}$ and $\mathrm{N}$ stages, and surgery were all independent prognostic predictors for the OS rate. Multivariate survival analysis of patients with bone-related metastases also showed that the metastatic sites, age, race, Gleason score, tumor T stage, radiotherapy, and chemotherapy were all independent prognostic predictors for the OS rate. In patients of the younger-aged group with a single metastatic site, patients with NRLN metastasis had a better OS rate than those with bone metastasis, while patients with liver metastasis had the worst OS rate. Moreover, in patients of the younger-aged group with multiple metastatic sites, there was no statistical 
difference in the OS rate of patients with bone + NRLN metastasis from patients with bone + lung metastasis. Compared to the results of patients with bone + NRLN metastasis, the OS rates of patients with bone + brain and bone + liver metastasis were poor. However, patients with bone + liver metastasis had the worst OS rate. In addition, in patients in the elderly-aged group with multiple metastasis sites, the OS rate of patients with bone + liver or bone + lung metastasis was worse than those of patients with of bone + NRLN metastasis, while patients with bone + liver metastasis has a higher risk of death than patients with bone + lung metastasis.

The reason for the observed high incidence of prostate cancer metastasis to the bone could be because of the interaction between metastatic prostate cancer cells and the bone microenvironment or because of the ability of the bone to attract tumor cells through the production and release of chemokines $[24,25]$. Moreover, many age-related factors, including immune response and chronic inflammation, could also play a role in prostate cancer metastasis [26, 27]. The "seed and soil hypothesis" may partly explain the phenomenon of different metastasis sites and patterns for cancer metastasis [28]. Our current research revealed that older Caucasians and younger African Americans were more likely to develop $\mathrm{mPCa}$, while younger patients with $\mathrm{mPCa}$ had higher $\mathrm{T}$ and $\mathrm{N}$ stages, which was consistent with previous findings [17]. In the current study, we selected the age of 70 years as the cut-off value. This age was selected for the following reasons: 1 ). The median age of the cohort of samples was 70 years old, 2). The X-tile software was used to select these three groups of age stratification and an age of less than 70 years old showed the best prognosis, and 3 ). Culp et al. showed that an age $\geq 70$ years was a risk factor for patients undergoing local therapy to be associated with an increased risk of cancer-specific death [29].

Our current study demonstrated that, in elderly patients, the prognosis of prostate cancer patients with bone, NRLN, or lung metastasis is similar. This may be because this group of patients had other diseases or related complications; however, this study does not provide proof in support of this hypothesis and, thus, further prospective studies are required. Furthermore, patients with bone-related metastases, such as bone + lung or bone + NRLN metastasis also showed similar rates of OS in the younger group, whereas patients with bone + liver or bone + brain metastasis in the elderly age group had a poor OS rate. According to previous studies, prostate cancer patients with bone \pm NRLN metastasis were generally treated locally, through cytoreductive prostatectomy or radiotherapy to improve prognosis [30, 31]. However, most of these studies excluded prostate cancer patients with visceral metastasis, leading to a poor prognosis of patients with visceral metastasis [32]. Our current data indicate that prostate cancer with bone + lung or bone + NRLN metastasis had similar prognosis in younger patients; thus, we may consider more radical treatment options to improve their prognosis. In addition, the elderly-aged group of patients with prostate cancer that had bone + lung metastasis had a higher death risk than those with bone + NRLN metastasis. We therefore, speculate that treatment of prostate cancer patients with metastasis could be more personalized to improve the survival rate of patients as well as the quality of life. Thus, our current study suggests that 1) differences in the baseline characteristics of $\mathrm{mPCa}$ cases, such as age, could alter the treatment options and survival rates of patients; 2) our current data could help us to better understand the biological characteristics of the disease, leading to the development of novel treatment strategies [33]. For example, individuals with visceral metastasis often had a poor prognosis; thus, metastasis-directed treatment options led to improving the prognosis of $\mathrm{mPCa}$ [34].

To date, the treatment of prostate cancer that is selected depends on the stage of the disease, the Gleason score, and the PSA level for surgery and chemical/radiotherapy; however, age and patient health, and persons' views of treatment effectiveness, and their possible side effects should also be taken into account, in addition to quality of life and life expectations [35-39]. Furthermore, based on age grouping, patients with different types of prostate cancer metastasis had different overall survival rates; for example, in a single metastases organ site, our current study showed that cases of prostate cancer with NRLN metastasis had a lower risk of death than those with bone metastases in the younger group. Adnan et al. have also reported that the prognosis of patients with NRLN metastasis was better than those with bone metastasis [31]. However, Shou et al. demonstrated that there was no difference in prognosis between patients with lung and bone metastasis [40]. In addition, our current findings show that patients with liver metastases had the worst overall survival, which is consistent with the findings from a previous study showing that prostate cancer with liver metastasis was associated with a shorter overall survival time [41]. Indeed, the probable reason for this finding is because prostate cancer with liver metastasis is often associated with neuroendocrine differentiation (NED) [42], which leads to an increase in tumor cell dedifferentiation, androgen receptor deficiency, and resistance to hormone therapy [43]. 
However, our research does have some limitations; for example, we were unable to collect data on endocrine therapy and other variables related to transfer loads, such as quantity, size, and exact location from the SEER database. Moreover, information regarding specific metastasis sites was only available in the SEER database after 2010. Because of this, we may not be able to ensure an adequate sample size and follow-up duration. In addition to the age at diagnosis, several other factors may also affect the overall survival. For example, chemotherapy, radiation therapy, and surgery may be more widely available to young patients with $\mathrm{mPCa}$, whereas elderly patients may have complications that lead to disease progression. Thus, future study should further verify our current data.

\section{Conclusions}

In conclusion, patients with lung metastases or younger patients ( $\leq 70$ years old) with bone + lung metastases had better prognosis. Thus, patients with other organic metastasis could be treated more aggressively to achieve better overall survival.

\section{Acknowledgement}

This work was supported in part by a grant from the National Natural Science Foundation of China (\#81472389) and Shanghai Municipal Health Planning Commission key project (20124008).

\section{Competing Interests}

The authors have declared that no competing interest exists.

\section{References}

1. Torre L, Bray F, Siegel R, Ferlay J, Lortet-Tieulent J, Jemal A. Global cancer statistics, 2012. CA Cancer J Clin. 2015; 65: 87-108.

2. Siegel RL, Miller KD, Jemal A. Cancer statistics, 2018. CA Cancer J Clin. 2018; 68: 7-30.

3. McGuire S. World Cancer Report 2014. Geneva, Switzerland: World Health Organization, International Agency for Research on Cancer, WHO Press, 2015. Adv Nutr. 2016; 7: 418-9.

4. Hankey B, Feuer E, Clegg L, Hayes R, Legler J, Prorok P, et al. Cancer surveillance series: interpreting trends in prostate cancer--part I: Evidence of the effects of screening in recent prostate cancer incidence, mortality, and survival rates. J Natl Cancer Inst. 1999; 91: 1017-24.

5. Miller KD, Siegel RL, Lin CC, Mariotto AB, Kramer JL, Rowland JH, et al. Cancer treatment and survivorship statistics, 2016. CA Cancer J Clin. 2016; 66: 271-89.

6. Gandaglia G, Abdollah F, Schiffmann J, Trudeau V, Shariat SF, Kim SP, et al. Distribution of metastatic sites in patients with prostate cancer: A population-based analysis. Prostate. 2014; 74: 210-6.

7. Hess KR, Varadhachary GR, Taylor SH, Wei W, Raber MN, Lenzi R, et al. Metastatic patterns in adenocarcinoma. Cancer. 2006; 106: 1624-33.

8. Long M, Husband J. Features of unusual metastases from prostate cancer. Br J Radiol. 1999; 72: 933-41.

9. Vinjamoori $\mathrm{AH}$, Jagannathan JP, Shinagare $\mathrm{AB}$, Taplin $\mathrm{ME}$, Oh WK, Van den Abbeele AD, et al. Atypical metastases from prostate cancer: 10-year experience at a single institution. AJR Am J Roentgenol. 2012; 199: 367-72.

10. Gillessen S, Attard G, Beer T, Beltran H, Bossi A, Bristow R, et al. Management of Patients with Advanced Prostate Cancer: The Report of the Advanced Prostate Cancer Consensus Conference APCCC 2017. Eur Urol. 2018; 73: 178-211.

11. Moul JW. Yes or no to local therapy for oligometastatic prostate cancer? Nat Rev Urol. 2018.
12. Stattin K, Sandin F, Bratt O, Lambe M. The Risk of Distant Metastases and Cancer Specific Survival in Men with Serum Prostate Specific Antigen Values above $100 \mathrm{ng} / \mathrm{ml}$. J Urol. 2015; 194: 1594-600.

13. Rusthoven C, Carlson J, Waxweiler T, Yeh N, Raben D, Flaig T, et al. The prognostic significance of Gleason scores in metastatic prostate cancer. Urol Oncol. 2014; 32: 707-13.

14. De Vergie S, Gaschignard N, Baron M, Branchereau J, Luyckx F, Butel T, et al. [Long-term outcomes of prostate cancer patients with lymph nodes metastasis after radical prostatectomy and pelvic lymph node dissection]. Prog Urol. 2018; 28: 25-31.

15. Cooperberg M, Freedland S, Pasta D, Elkin E, Presti J, Amling C, et al. Multiinstitutional validation of the UCSF cancer of the prostate risk assessment for prediction of recurrence after radical prostatectomy. Cancer. 2006; 107: 2384-91.

16. Cooperberg M, Broering J, Carroll P. Risk assessment for prostate cancer metastasis and mortality at the time of diagnosis. J Natl Cancer Inst. 2009; 101: 878-87.

17. Pettersson A, Robinson D, Garmo H, Holmberg L, Stattin P. Age at diagnosis and prostate cancer treatment and prognosis: a population-based cohort study. Ann Oncol. 2018; 29: 377-85.

18. Halabi S, Kelly WK, Ma $\mathrm{H}$, Zhou $\mathrm{H}$, Solomon $\mathrm{NC}$, Fizazi $\mathrm{K}$, et al Meta-Analysis Evaluating the Impact of Site of Metastasis on Overall Survival in Men With Castration-Resistant Prostate Cancer. J Clin Oncol. 2016; 34: 1652-9.

19. Gandaglia G, Karakiewicz PI, Briganti A, Passoni NM, Schiffmann J, Trudeau $\mathrm{V}$, et al. Impact of the Site of Metastases on Survival in Patients with Metastatic Prostate Cancer. Eur Urol. 2015; 68: 325-34.

20. Edge S, Compton C. The American Joint Committee on Cancer: the 7th edition of the AJCC cancer staging manual and the future of TNM. Ann Surg Oncol. 2010; 17: 1471-4.

21. Camp R, Dolled-Filhart M, Rimm D. X-tile: a new bio-informatics tool for biomarker assessment and outcome-based cut-point optimization. Clin Cancer Res. 2004; 10: 7252-9.

22. Fitzmaurice C, Collaboration GBoDC. Global, regional, and national cancer incidence, mortality, years of life lost, years lived with disability, and disability-adjusted life-years for 29 cancer groups, 2006 to 2016: A systematic analysis for the Global Burden of Disease study. Journal of Clinical Oncology. 2018; 36: 1568-

23. Hanahan D, Weinberg RA. Hallmarks of cancer: the next generation. Cell. 2011; 144: 646-74.

24. Tsingotiidou A, Zotalis G, Jackson K, Sawyers C, Puzas J, Hicks D, et al. Development of an animal model for prostate cancer cell metastasis to adult human bone. Anticancer Res. 2001; 21: 971-8

25. Jacob K, Webber M, Benayahu D, Kleinman H. Osteonectin promotes prostate cancer cell migration and invasion: a possible mechanism for metastasis to bone. Cancer Res. 1999; 59: 4453-7.

26. Guo Z, Xing Z, Cheng X, Fang Z, Jiang C, Su J, et al. Somatostatin Derivate (smsDX) Attenuates the TAM-Stimulated Proliferation, Migration and Invasion of Prostate Cancer via NF-kappaB Regulation. PLoS One. 2015; 10: e0124292.

27. Nguyen DP, Li J, Tewari AK. Inflammation and prostate cancer: the role of interleukin 6 (IL-6). BJU Int. 2014; 113: 986-92.

28. Pienta KJ, Robertson BA, Coffey DS, Taichman RS. The cancer diaspora: Metastasis beyond the seed and soil hypothesis. Clin Cancer Res. 2013; 19: 5849-55.

29. Culp S, Schellhammer P, Williams M. Might men diagnosed with metastatic prostate cancer benefit from definitive treatment of the primary tumor? A SEER-based study. Eur Urol. 2014; 65: 1058-66.

30. Padhani AR, Lecouvet FE, Tunariu N, Koh DM, De Keyzer F, Collins DJ, et al. Rationale for Modernising Imaging in Advanced Prostate Cancer. Eur Urol Focus. 2017; 3: 223-39.

31. Clarke N, Ali A, Mistry H, Hoyle A. The importance of non-regional lymph nodes in assigning risk in primary metastatic prostate cancer. Journal of Clinical Oncology. 2018; 36: 227-.

32. Decaestecker K, De Meerleer G, Lambert B, Delrue L, Fonteyne V, Claeys T, et al. Repeated stereotactic body radiotherapy for oligometastatic prostate cancer recurrence. Radiat Oncol. 2014; 9: 135

33. Halabi S, Owzar K. The importance of identifying and validating prognostic factors in oncology. Semin Oncol. 2010; 37: e9-18.

34. Ost P, Bossi A, Decaestecker K, De Meerleer G, Giannarini G, Karnes R, et al. Metastasis-directed therapy of regional and distant recurrences after curative treatment of prostate cancer: a systematic review of the literature. Eur Urol. 2015; 67: 852-63.

35. Lu-Yao G, Albertsen P, Moore D, Shih W, Lin Y, DiPaola R, et al. Outcomes of localized prostate cancer following conservative management. JAMA. 2009; 302: $1202-9$

36. Picard J, Golshayan A, Marshall D, Opfermann K, Keane T. The multi-disciplinary management of high-risk prostate cancer. Urol Oncol. 2012; 30: 3-15.

37. Mohan R, Schellhammer P. Treatment options for localized prostate cancer. Am Fam Physician. 2011; 84: 413-20.

38. Sartor O, de Bono J. Metastatic Prostate Cancer. N Engl J Med. 2018; 378: $1653-4$. 
39. Di Blasio C, Rhee A, Cho D, Scardino P, Kattan M. Predicting clinical end points: treatment nomograms in prostate cancer. Semin Oncol. 2003; 30: $567-86$.

40. Shou J, Zhang Q, Wang S, Zhang D. The prognosis of different distant metastases pattern in prostate cancer: A population based retrospective study. Prostate. 2018; 78: 491-7.

41. Armstrong AJ, Garrett-Mayer ES, Yang YC, de Wit R, Tannock IF, Eisenberger $\mathrm{M}$. A contemporary prognostic nomogram for men with hormone-refractory metastatic prostate cancer: a TAX327 study analysis. Clin Cancer Res. 2007; 13: 6396-403.

42. Pouessel D, Gallet B, Bibeau F, Avances C, Iborra F, Senesse P, et al. Liver metastases in prostate carcinoma: clinical characteristics and outcome. BJU Int. 2007; 99: 807-11.

43. Alfredo B, Luigi D, Alessandra M, Maurizio B, Mauro M, Mirella T, et al. Circulating neuroendocrine markers in patients with prostate carcinoma. Cancer. 2000; 88: 2590-7. 